\title{
Evaluating cardiomegaly by radiological cardiothoracic ratio as compared to conventional echocardiography
}

Volume 9 Issue 2 - 2017

\section{Editorial}

It is commonly observed in our routine clinical practice that a significant number of echocardiograms are requested in hospitalized patients based on the sole interpretation of admission chest radiography as having cardiomegaly without making any detailed appropriate measurement. It is very important to adequately evaluate cardiac dimensions in the clinical setting. Therefore, assessing heart size by measuring the cardiothoracic ratio (CTR) still remains as a useful diagnostic tool in chest radiography evaluation. ${ }^{1-3}$ Chest radiography is an auxiliary diagnostic method that is widely utilized since it is easy to perform, readily available, inexpensive, and allows assessment of heart size and its changes over time. Chest radiographderived cardiothoracic ratio is a very simple and useful measure which can serve as an index of cardiac size in screening cardiomegaly for cardiovascular diseases..$^{3-5}$ The CTR is expressed as the ratio of the transverse diameter of the heart to the maximum internal diameter of the thoracic cavity. In other words the CTR is calculated by dividing the cardiac diameter by the thoracic diameter as measured on postero-anterior chest radiography. A value of 50\% (0.5) is generally considered to indicate the upper limit of normal. ${ }^{2-6}$ However, there are some cardiac and extra-cardiac factors that may influence this measurement. Measure variations can be found due to the patient's biotype and physiological status, scoliosis, pectus excavatum, the size of the lungs, the breathing phase, the cardiac cycle phase, and heart rate at the time of examination. ${ }^{1,7}$

The cardiothoracic ratio was first described in 1919. Later on, several studies have shown that an enlarged cardiothoracic ratio $>0.5$ on a postero-anterior radiograph has a significant value in the outcome and prognostic evaluation in healthy men, in the elderly, and in a variety of patients with congenital and acquired heart diseases..$^{8-16}$ Postero-anterior radiologic films taken at a standard distance $(180 \mathrm{~cm})$ are the gold standard on which to base cardiothoracic ratio measurements. On the other hand, antero-posterior chest radiography has serious limitations preventing its use for the precise measurement of CTR. When radiation enters from the anterior incidence it makes the cardiac diameter appear larger because the heart is located toward the anterior thorax. Besides, the shorter distance between the radiation source and the imaging cassette film results in a larger image. Hence, it overestimates not only the cardiac diameter but also the thoracic diameter. This mentioned CTR of $>0.5$ was found to be a good predictor of subsequent left ventricular systolic dysfunction on echocardiography diagnosed in a heart failure clinic in primary care setting. ${ }^{17}$ Accurate determination of the heart size including the diameter of each of the four chambers of the heart is a very important measurement which helps physicians in evaluating the etiology of cardiomegaly. Although, echocardiography is commonly superior to chest radiography in providing a better assessment of heart chamber size, it has been shown a satisfactory correlation between the CTR

\author{
Osmar Antonio Centurión, Karina $\mathrm{E}$ \\ Scavenius, ${ }^{1,2}$ Luis M Miño, ${ }^{2}$ Orlando R \\ Sequeira ${ }^{2}$ \\ 'Department of Health Sciences?s Investigation, Sanatorio \\ Metropolitano, Fernando de la Mora, Paraguay \\ ${ }^{2}$ Division of Cardiovascular Medicine, Clinic Hospital, Asunci
}

Correspondence: Osmar Antonio Centurión, Professor of Medicine, Asuncion National University, Department of Health Sciences $\square$ s Investigation, Sanatorio Metropolitano, Teniente Ettiene $215 \mathrm{c} /$ Ruta Mariscal Estigarribia, Fernando de la Mora, Paraguay, Email osmarcenturion@hotmail.com

Received: June 27, 2017 | Published: June 28, 2017

and the heart size found at autopsy studies. ${ }^{2}$ Though heart chamber size can be determined by chest radiography, the diagnosis can be made more accurately by other more expensive imaging modalities. For example, cardiac echocardiography, magnetic resonance imaging (MRI) and computed tomography (CT scan) were found to be superior to chest radiography in providing a better assessment of heart chamber size and function. ${ }^{18-22}$ Echocardiography was found to have a superior sensitivity and specificity in determining cardiac chamber size. ${ }^{6}$ Moreover, MRI and CT scan imaging modalities can give accurate assessment of cardiac chamber size and function. Kadhum A et al., ${ }^{9}$ demonstrated that CTR had a fairly high sensitivity (85\%) but low specificity (14\%) when used to determine cardiomegaly. When performing detailed quantitative analysis for a more objective numerical estimation of the cardiac size, echocardiography should be considered the gold standard because of its high sensitivity and specificity.

With current technology of imaging modalities, several investigational studies have tried to improve the conventional CTR utilizing newer measurements of cardiac size. New measurements derived from chest radiography, CT scan and MRI, angiographic and radionuclide imaging measurements, combined with a variety of echocardiographic parameters have been used to assess cardiac size and left ventricular function. ${ }^{18-22}$ Although, previous studies have shown no correlation between the CTR and markers of diastolic dysfunction, the results are different in patients with systolic dysfunction. ${ }^{23}$ Indeed, there are data that suggest that an increased or increasing CTR may be useful as a surrogate of progressive left ventricular dilatation in patients with known left ventricular systolic 
dysfunction. ${ }^{24}$ However, the positive predictive value in the diagnosis of left ventricular systolic dysfunction is rather low. ${ }^{25}$ Hammermeister KE et al., ${ }^{11}$ demonstrated a sensitivity and specificity of the CTR of $\geq 0.5$ to detect left ventricular enlargement of $88 \%$ and $41 \%$, while those to detect reduced ejection fraction were $86 \%$ and $35 \%$, respectively. Chon SB et al., ${ }^{26}$ found the sensitivity and specificity of CTR to diagnose congestive cardiomegaly with the criterion of $\geq 0.5$ was $61 \%$ and $54 \%$ respectively, showing lower sensitivity and slightly higher specificity. Schlett CL et al., ${ }^{19}$ reported interesting data. They showed that the cardiac diameter, but not the CTR, was significantly correlated with the left ventricular size, the well-known predictor of cardiovascular morbidity and mortality. However, there are several studies that emphasize the utility of CTR in different entities. ${ }^{27-31}$ Even CTR values that are within normal limits were found to have clinical implication. It was observed that a CTR $\geq 0.42$ is associated with higher mortality in patients undergoing coronary angiography. ${ }^{4}$ Giamouzis $\mathrm{G}$ et al., ${ }^{14}$ demonstrated that a baseline CTR $>0.50$ is associated with increased mortality and morbidity in ambulatory patients with chronic heart failure.

Moreover, in heart failure patients who are in the list for cardiac transplantation, an enlarged CTR was found to be an important prognostic tool. ${ }^{16}$ In addition, an enlarged CTR was demonstrated to be an important predictor of left ventricular systolic dysfunction in a community population $;{ }^{17}$ and it was also associated to sudden cardiac death. ${ }^{32}$

\section{Conclusion}

In conclusion, although CTR is an important tool in the clinician's armamentarium in the diagnostic and therapeutic management of patients, echocardiography is commonly superior to chest radiography in providing a better assessment of cardiomegaly and clearly demonstrated a better sensitivity and specificity for that purpose. Therefore, we should be reminded of the fact that when we see an enlarged CTR on chest radiography it may not be cardiomegaly. The echocardiography will tell us the truth.

\section{Acknowledgements}

None.

\section{Conflicts of interest}

Author declares there are no conflicts of interest.

\section{Funding}

None.

\section{References}

1. Nakamori N, Doi K, MacMahon H, et al. Effect of heart-size parameters computed from digital chest radiographs on detection of cardiomegaly. Potential usefulness for computer-aided diagnosis. Invest Radiol. 1991;26(6):546-550.

2. Murphy ML, Blue LR, Thenabadu PN, et al. The reliability of the routine chest roentgenogram for determination of heart size based on specific ventricular chamber evaluation at postmortem. Invest Radiol. 1985;20(1):21-25.

3. Nickol K, Wade AJ. Radiographic heart size and cardiothoracic ratio in three ethnic groups: a basis for a simple screening test for cardiac enlargement in men. British Journal of Radiology. 1982;55(654):399-403.

4. Zaman MJ, Sanders J, Crook AM, et al. Cardiothoracic ratio within the "normal" range independently predicts mortality in patients undergoing coronary angiography. Heart. 2007;93(4):491-494.
5. Hada Y. Cardiothoracic ratio. J Cardiol. 1995;26(1):51-54.

6. Kadhum AAH, Sharif S, Abd-Hazaa M. Validity of Chest X-Ray In Estimation of Cardiac Size in Comparison To Echocardiography. MJBU. 2007;25(2):48-51

7. Lupow JB, Sivak SL, Boss D. The Accuracy of the Cardiothoracic Ratio as a Predictor of Cardiac Enlargement and Dysfunction. Acad Emerg Med. 2003;9(5):462.

8. Hemingway H, Shipley M, Christie D, et al. Is cardiothoracic ratio in healthy middle aged men an independent predictor of coronary heart disease mortality? Whitehall study 25 year follow up. BMJ. 1998;316:1353-1354.

9. Frishman WH, Nadelmann J, Ooi WL, et al. Cardiomegaly on chest $\mathrm{X}$-ray: prognostic implications from a ten-year cohort study of elderly subjects: a report from the Bronx Longitudinal Aging Study. Am Heart J. 1992;124(4):1026-1030.

10. Dimopoulos K, Giannakoulas G, Bendayan I, et al. Cardiothoracic ratio from postero-anterior chest radiographs: a simple, reproducible and independent marker of disease severity and outcome in adults with congenital heart disease. Int J Cardiol. 2013;166(2):453-457.

11. Hammermeister KE, Chikos PM, Fisher L, et al. Relationship of cardiothoracic ratio and plain film heart volume to late survival. Circulation. 1979;59(1):89-95.

12. Zaman MJ, Sanders J, Crook AM, et al. Cardiothoracic ratio within the 'normal' range independently predicts mortality in patients undergoing coronary angiography. Heart. 2007;93(4):491-494.

13. Cohn JN, Johnson GR, Shabetai R, et al. Ejection fraction, peak exercise oxygen consumption, cardiothoracic ratio, ventricular arrhythmias, and plasma norepinephrine as determinants of prognosis in heart failure. The V-HeFT VA Cooperative Studies Group. Circulation. 1993;87(6):VI5V16.

14. Giamouzis G, Sui X, Love TE, et al. A propensity-matched study of the association of cardiothoracic ratio with morbidity and mortality in chronic heart failure. Am J Cardiol. 2008;101(3):343-347.

15. Ernst ER, Shub C, Bailey KR, et al. Radiographic measurements of cardiac size as predictors of outcome in patients with dilated cardiomyopathy. J Card Fail . 2001;7(1):13-20.

16. Berman M, Aravot D, Ben-Gal T, et al.Cardiothoracic ratio: important prognostic tool in heart failure patients who are candidates for heart transplantation. Transplant Proc. 2000;32:727-728.

17. Shah S, Davies MK, Cartwright D, et al. Management of chronic heart failure in the community: role of a hospital based open access heart failure service. Heart. 2004;90(7):755-759.

18. Browne RFJ, O'Reilly G, McInerney D. Extraction of the twodimensional cardiothoracic ratio from digital PA chest radiographs: correlation with cardiac function and the traditional cardiothoracic ratio. J Digit Imaging. 2004;17(2):120-123.

19. Schlett CL, Kwait DC, Mahabadi AA, et al. Simple area-based measurement for multidetector computed tomography to predict left ventricular size. Eur Radio. 2010; 120(7):1590-1596.

20. Philbin EF, Garg R, Danisa K, et al. The relationship between cardiothoracic ratio and left ventricular ejection fraction in congestive heart failure. Digitalis Investigation Group. Arch Intern Med. 1998;158(5):501-506.

21. ClarkAL, Coats AJ. Unreliability of cardiothoracic ratio as a marker of left ventricular impairment: comparison with radionuclide ventriculography and echocardiography. Postgrad Med J. 2000;76(895):289-291.

22. Kono T, Suwa M, Hanada H, et al. Clinical significance of normal cardiac silhouette in dilated cardiomyopathy--evaluation based upon echocardiography and magnetic resonance imaging. Jpn Circ J. 1992;56(4):359-365. 
23. Summers RL, Woodward LH, Kolb JC. Correlation of radiographic cardiothoracic ratio with cardiac function in patients with acute congestive heart failure. Emerg Radiol . 1999;6(3):153-156.

24. Petrie MC. It cannot be cardiac failure because the heart is not enlarged on the chest X-ray. Eur J Heart Fail. 2003;5(2):117-119.

25. Chana HS, Martin CA, Cakebread HE, et al. Diagnostic accuracy of cardiothoracic ratio on admission chest radiography to detect left or right ventricular systolic dysfunction: a retrospective study. J Royal Soc Med. 2015;108(8):317-324.

26. Chon SB, Oh WS, Cho JH, et al. Calculation of the Cardiothoracic Ratio from Portable Anteroposterior Chest Radiography. J Korean Med Sci. 2011;26(11):1446-1453.

27. Tomita H, Yamashiro T, Matsuoka S, et al. Changes in Cross-Sectional Area and Transverse Diameter of the Heart on Inspiratory and Expiratory Chest CT: Correlation with Changes in Lung Size and Influence on Cardiothoracic Ratio Measurement. PLoS One. 2015;10(7):e0131902.
28. Liou, KY, Liou HH, et al. Association between peripheral arterial occlusive disease and cardiothoracic ratio in patients on chronic hemodialysis. Sci Rep. 2016;6:38458.

29. Okute Y, Shoji T, Hayashi T, et al. Cardiothoracic Ratio as a Predictor of Cardiovascular Events in a Cohort of Hemodialysis Patients. $J$ Atheroscler Thromb. 2017;24(4):412-421.

30. Esmail H, Oni T, Thienemann F, et al. CardioThoracicRatio Is Stable, Reproducible and Has Potential as a ScreeningTool for HIV1 Related Cardiac Disorders in Resource Poor Settings. PLoS One. 2016;11(10):e0163490.

31. Ito K, Ookawara S, Ueda Y, et al. A Higher Cardiothoracic Ratio Is Associated with 2-Year Mortality after Hemodialysis Initiation. Nephron Extra. 2015;5(3):100-110.

32. Nolan J, Batin PD, Andrews R, et al. Prospective study of heart rate variability and mortality in chronic heart failure results of the United Kingdom heart failure evaluation and assessment of risk trial (UKHeart). Circulation. 1998;98(15):1510-1516. 